\title{
Contemporary challenges in cartographic education
}

\author{
David Fairbairn ${ }^{a}$ * \\ ${ }^{a}$ Newcastle University, Newcastle upon Tyne,UK; david.fairbairn@newcastle.ac.uk \\ * Corresponding author
}

Keywords: Education in cartography, ICA Commission on Education and Training

This paper is focussed on the work and remit of the ICA's Commission on Education and Training (CET), presenting a reflection by the retiring chair of the current issues which affect the work of Commission members and all engaged in current education and training of students of cartography around the world.

The nature and development of cartography as an academic and professional discipline has been discussed through many presentations, both conceptual and applied, and in various arenas and communities, over the past half century. As cartographic practice became standardised in the $20^{\text {th }}$ century, so educational and instructional materials describing and analysing the discipline conveyed a relatively uniform message, ensuring that the audience of learners were educated and trained positively to an agreed agenda. In effect, a subtle, as yet unwritten, 'Body of Knowledge' was developed and elucidated in educational materials, notably textbooks on cartography, in the last few decades of the last century (Kessler, 2018).

It was during these years, however, that cartography developed as a discipline far beyond its initial roots as a map-making technology. The technology of map-making certainly changed completely, and a host of other aspects were incorporated, from metrical analysis of historical map documents to gender-oriented investigations of mapping activity; from the integration and importance of cartography in contemporary geospatial data handling to the role of volunteer map-making; from the psychology of map interaction and decision making to the mathematics of map projections and multi-dimensional data representation; and many, many other activities and issues which must be included in educational programmes in cartography.

It is the establishment, adoption and maintenance of a Body of Knowledge (BoK) which is one of the main challenges (this paper presents 11 , in bold below) and, if successfully met, it can assist in ensuring that cartographic education and training develops as required in the next few decades (Fairbairn, 2017). The further challenges highlighted in this paper can form the basis for further investigation by the CET in the future. This listing of issues is informed by a number of contemporary changes in technology, by closer integration of cartography with other geospatial sciences, by research achievements and investigations in the field, by advances in educational praxis, by demands on cartography by a host of other activities, and by consequent recognition of the discipline by learned and professional bodies.

One of the main purposes in developing a Body of Knowledge is to encompass and facilitate curriculum design. As the widening scope of cartography will be reflected in the developing BoK (most notably in cartography's contribution to GIS), curriculum design must be flexible and innovative enough to cope with more numerous and wider, though focussed and integrated, topics. The admirable, existing BoK in Geographic Information Science and Technology, already being reviewed and enhanced, but omitting many specific cartographic principles, is a possible framework for incorporating these. Alternatively there are sound arguments for a uniquely cartographic BoK, and this enterprise is certainly an ICA-approved pursuit.

Also within the BoK, the theoretical foundations for the study of cartography must be elucidated and moved from the research agenda to the educational curriculum. A revised Research Agenda developed under ICA auspices and a focussed Body of Knowledge are synergistic documents, with interdependent content in one directing content in the other. Such documents may be perceived by many to be overly conceptual, un-related to everyday mapping activity. In terms of cartographic production in the past 50 
years, we have moved far from the standardised methods mentioned earlier, applied by every commercial and governmental mapping organisation. The activity of map-making has adopted a host of alternative methods, and artefacts, data-sets and representations are created and 'mashed-up' by an increasingly wide range of individuals and groups with highly variable experiences, expertise and understanding of cartographic procedures. In terms of 'organised' cartography in multi-employee companies, government and non-government agencies, academic and research groups, and associated industrial and environmental companies, a further challenge is understanding what employers want from graduates in cartography and GIS. The delivery of education in cartography is an academic activity, but it must be done in a manner which demonstrates relevance to the community which relies on the skills of an educated workforce.

In some cases the cartographic community, notably its educators, may have to direct their attention outside the classroom and convince the fragmenting industry that cartographic principles are vital for effective management and communication of information, and that the products of cartographic education (the graduates from educational programmes) are serious and informed potential employees with much to offer a wide range of human activity. Such recognition by those outside the academy can be encouraged by seeking and receiving professional accreditation from awarding bodies such as industry associations, learned societies, educational authorities and public bodies. The landscape of professional recognition in the disciplines of cartography and GIS is highly varied, geographically, institutionally, legally, and pedagogically. The fluid nature of the disciplines, and in particular their fuzzy distinction from a host of other geomatics, geospatial, engineering, environmental, and social activities means that cartographic education must acknowledge and address its interaction with education in many other sciences. Linking cartographic education and its principles with related education in other closely related geo-disciplines is particularly important. Common messages must be presented stressing cartography's importance and relevance.

At the possible wider levels mentioned above, experiences and lessons learned from teaching cartography and GIS to a broad range of non-specialists must be documented: cartographic principles must be shown to be important and relevant to all those engaged in handling maps and mapping data. Stressing the importance of such principles is especially vital when education is done at a distance: the Commission has long been interested in those activities which develop on-line educational resources and look at innovative ways of delivering education widely to large audiences outside formal educational establishments. We already have reports on mature and effective resources in the form of MOOCs, distance learning courses, and online training modules (e.g. Robinson and Nelson, 2015). Such methods of delivery for cartographic education have proven popular and efficient: educators must ensure continued relevance, update, and diligence, in managing these activities.

In addition to content development and assessment frameworks, it is technical requirements which are often perceived as major blocks to effective use of in-line educational resources. Technical support requirements are critical in every form of cartographic education: in the past replication of map reproduction labs was prohibitive for most educational establishments; today it is the acquisition of a full range of software which mitigates against full exposure to the varied range of cartographic and geospatial data handling activity as practised in the 'real world'. The generosity of some software providers is widely acknowledged in educational institutions, and many of the software products are generic enough to be able to demonstrate the required cartographic principles in a non-partisan manner. However, in many cases employers are seeking specific training skills in particular packages and this can be difficult to provide within a formal educational programme.

Recent additions to the 'wish-list' of employers, however, have been related to abilities in coding and computer programming. Luckily, the most commonly sought skill is ability to write code in Python or Javascript. These are open source, rather than a commercial, products, and hence can be acquired by any educational establishment. The use of open source software and datasets in geospatial and cartographic 
education is becoming increasingly important, and their effective integration with traditional (and indeed contemporary) curricula in cartographic education is clearly a further challenge.

This paper has outlined a number of challenges facing cartographic education. Like the wider discipline, education in cartography is delivered by capable and dedicated individuals, each with interests in the development of the discipline in an increasingly diverse and varied educational arena. The Commission is intent on addressing the challenges outlined, promoting effective and high-quality cartographic education. 